seen, is also appreciably darkened by its preserve. When the star is black and the card behind it white, the illusion is still present. though a brightening of the black takes the place of the darkening just mentioned.

The rationale of the illusion is easy. The outer ring is really transparent, and the edge of the card is really seen through it. The transparency of the ring strongly suggests the transparency of the centre, a suggestion that we accept the more easily because the rapid rotation changes the appearance of the central portion somewhat from its familiar resting appearance. The apparent darkening of the portion of the central part overlying the black card is to be similarly explained. It is especially interesting, however, as being clearly a psychological illusion, an "illusion of judgment," while the color illusions formerly so called are being shown to be physiological, arid largely, if not entirely, due to the mutual influence of adjacent portions of the retina.

A physiological explanation of this illusion seems hardly possible; and its psychical character is further attested by the ease with which it is corrected when the card remains stationary, and the unequal degree in which it seems to affect different observers.

\section{A SUGGESTION AS TO TOPOGRAPHIC MAPS.}

\section{BY ARThur P. DAVIS, LOS ANGELES, CALIFORNIA.}

WHILE the scientific and technical bodies of California and other States are agitating the question of topographic maps, educating the public on the question, and endeavoring to secure State appropriations and Government coöperation for such surveys, it may not be amiss to suggest other sources that might be made to furnish valuable contributions toward the same end. I refer to the very extensive and costly surreys made by engineers, promoters, and companies to determine the necessary information for the construction of railroads, irrigation systems, etc.

I have known cases where a large number of preliminary or trial lines have been run, the aggregate cost of which amounted to many times that of a good topographic map of the region under investigation, which would have shown all that the afore said surveys can show, and a great deal beside; for it is always an open question, whether the line finally determined upon is in reality the best in all respects, or whether some other, of the many untried possible routes might not be somewhat better or cheaper. All these possible routes would be shown by a good contour topographic map, and in addition tbereto it would serve as a valuable piece of data for any future additions or alterations in the work.

Another argument in favor of the contour map that ought to weigh strongly in its favor with the persons above referred to, is the philantbropic one, that such a map is a valuable and permanent contribution to science. A large percentage of the scientific discoreries that have contributed so prodigiously to the intellecinal and material advancement of the human race, have been made by persons working without the incentive of financial gain, and it is safe to say that few of them would bave been made, if that had been the only incentive followed.

I do not believe that engineers and capitalists in charge would prove less public spirited than others if their attention were properly directed to this matter; and if geologists and others actively interested would persistently present these facts to the proper persons, great good might result. The main point to be carried is the substitution of the plane table for the transit in making preliminary surreys.

Without a systematic method of accurate field-sketching, which is the essential principle of the plane table, topographic mapping on any extended scale is impossible. Properly handled, with triangulations to check locations, and level bench-marks to check elevations, and with stadia to assist in sketching, plane table work may be entirely accurate within any scale adopted, and serve not only for preliminary information upon which to locate routes for canals, railroads, etc., but is a permanent record of comprehensive information to guide all future engineering operations in the country included, so that ordinarily at least two or three times as much might be advantageously spent on the con- struction of contour maps as would be required for running preliminary lines, and still the company would profit by the substitution. If the labor expended upon the tremendous mass of material now on' record in the great engineering offices tbroughout the west $h$ ad been judiciously supplemented by field-sketching on the plane table, a very great addition would have been made to our topographic knowledge, and I believe that such results could be brought about by well-directed efforts on the part of the proper persons.

\section{LETTERS TO THE EDITOR.}

\section{*** Correspondents are requested to be as brief as possible. The vriter's name is in all cases required as proof of good faith. \\ On request in advance, one hundred copies of the number containing his communication will he furnished free to any correspondent. \\ The editor will be glad to publish any queries consonant with the character of the journal. \\ Pseudoauroræ.}

DR. HATCA's description of "Pseuloaurora Borealis" in your issue of Dec. 2, 1892, calls to mind a peculiar phenomenon which I once witnessed here, and which may have some bearing on pseudoauroræ in general if not on the pirticular species observed by Dr. Hatch.

About three years ago, as I was returning from the business part of the village of Plattsburgh, N. Y.. my attention was taken by two long. white, brilliant. quivering streamers in the southwest, which at times seemed to shoot up and nearly reach the zenith. This was an unusual direction for such a display, and I at once turned toward the north to note its character there. Buildings prevented a good view, but I saw several streamers though none so brilliant as those in the south-west. Hastily taking the phenomenon for a true display of the aurora. I hurried home, only noting on my way that the streamers were brighter now in one direction, and now in another. It was not until I had called others out to witness the display, and remained quiet myself for a moment, that I discovered that one very brilliant streamer seemed to be situated directly back of the known position of one of our arc lamps, and what was still more curious it refused to move from that suspicious position. This streamer varied remarkably in brightness, now being short and faint, and again long and brilliant. Along with these greater changes in intensity there were more rapid and lesser changes, and in addition to these a constant shimmering of the light. There were also slow wave-movements of brighter portions which ran from below upward, or crossed the streamer from left to right. It was movements of this nature, so like the curtain movements of the true aurora, that led me for the moment to refer the phenomenon to the aurora itself, and the many beams, which sometimes ran so high as to suggest a corona overbead, and which varied in relative intensity if one was moving about, only helped to confirm the error. Plattsburgh has had electric street-lamps for seven years or more, yet this one display stands practically alone by itself. The streamer which I studied most was over a lamp something more than a thousand feet away, and was viewed across some village lots with many buildings clustered around the position of the lamp. The lamp itself was thus hidden from view, though it hung over the centre of the street and could cast no high shadows save alone those of the top of the lamp and its wires. These. of course, helped to cut up the beam of light. I do not think that a dark arch was present, though I can conceive that one of Professor Hazen's shadows might have been thrown by a group of trees or buildings in such a manner as to produce one, had some convenient cloud been situated in the background. I attribute the phenomenon to the peculiar condition of the atmosphere at the time. We were in a very light frost-fog and the vertical and lateral movements of brighter waves were probably due to denser portions of this frost-cloud, drifting along with the air-currents. The varying light of the arc lamps served to make these movements seem the more complex. I think it very probable that color was in many places present, due to a halo encircling each lamp, although I do not recall having noticed it. From Dr. Hatch's description it would seem that the two phenomena are not the same, as when he retired from the lamps the "aurora" 